\title{
Understanding the Mental Health Needs of Metro Detroit's Veterans
}

T he recent challenges confronting the metropolitan Detroit area ("metro Detroit") are well known-the decline of the auto industry followed by high unemployment and eventual bankruptcy. As the region begins to turn around, however, information is needed about how its 225,000 veterans are faring. Little is known about the specific challenges these veterans face and whether the available benefits, services, and resources are supporting them sufficiently.

To inform investments in expanding or coordinating metro Detroit's mental health support to veterans, RAND was asked to document the types of mental health issues faced by veterans living in the region and to identify gaps in services targeted to veterans. Using a variety of methods, including a literature review, a review of publicly available information, stakeholder interviews, and interviews and focus groups with veterans, RAND has constructed a broad and detailed picture of the support landscape for metro Detroit veterans and identified areas where critical gaps remain.

\section{Common Mental Health Problems Among Veterans}

Studies of American veterans indicate that mental health problems are common. In particular, exposure to combat is significantly related to developing posttraumatic stress disorder (PTSD), depression, or both after service. Those who are younger, single, or unsatisfied with their romantic relationships also have a stronger correlation with PTSD. Furthermore, female service members are at increased risk for depression, while male service members are at increased risk for substance use.

Previous RAND research has noted that such postcombat mental health and cognitive conditions can have both direct and short-term consequences, as well as indirect and longer-term ones, and may be exacerbated or mitigated based upon individual resources and vulnerabilities. Postcombat mental health concerns also could include comorbid-

\footnotetext{
${ }^{1}$ The metropolitan Detroit area comprises Wayne, Oakland, and Macomb counties.
}

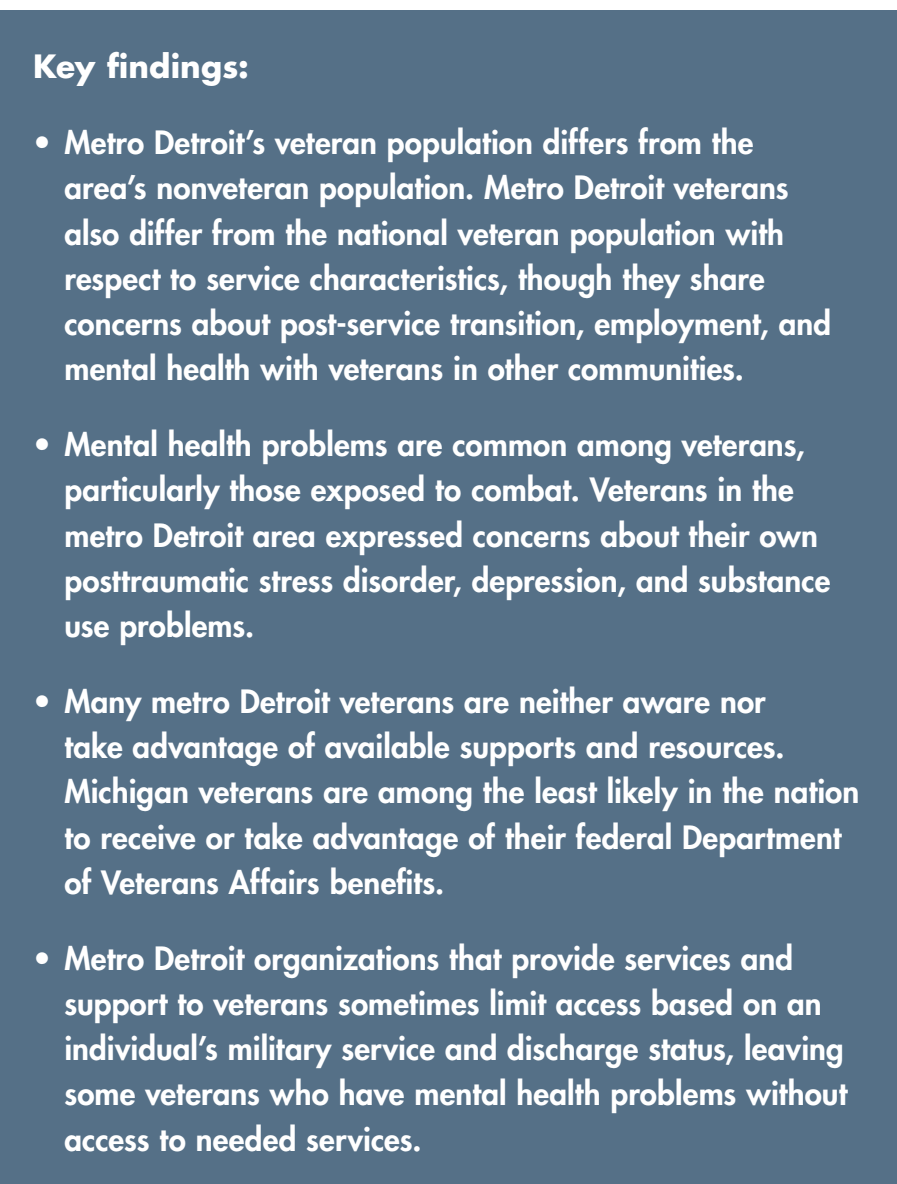

ity with other mental health problems (including substance misuse) and suicide; decreased physical health and mortality; decreased employment and productivity; homelessness; and negative marriage, parenting, and child outcomes.

\section{Metro Detroit Veterans and the Mental Health Challenges They Face}

Veterans in the metro Detroit area are predominantly male (90 percent, compared with fewer than half of nonveterans). Half of the veteran population is 65 years of age or older, compared with less than 20 percent of nonveterans ages 18 and older - and veterans are more likely to have a disability (29 percent, compared with 17 percent). 
Veterans in the metro Detroit area look similar to veterans nationally in terms of age, gender, and percentage with a service-connected disability. In the metro Detroit area specifically, however, veterans are more likely to be black and to have served during peacetime compared with veterans nationally. In addition, the proportion of post- $9 / 11$ veterans living in the region is much lower than the national profile of U.S. veterans.

When questioned about the major issues they have faced-from the time they separated from the military to the present day - metro Detroit veterans highlighted concerns with adjustment to civilian life and mental health problems. Beyond the loss of the support and regimentation of military life when they returned to civilian life, interviewees and focus group participants noted particular challenges with reestablishing relationships with family and friends, accessing needed services and benefits, and finding and maintaining meaningful employment. Interestingly, many of these veterans noted that the speed with which a service member returns to civilian life can be problematic; while historically a "decompression" period could take weeks, service members may now transition from combat to home in as little as three days.

Although resources and programs were available to aid them during their transition, many metro Detroit veterans indicated a lack of awareness of and access to these services. In fact, data from the U.S. Department of Veteran Affairs (VA) show that Michigan veterans are among the least likely in the nation to receive or take advantage of their federal benefits. In addition to difficulties navigating local and federal processes to access services and claim benefits, veterans noted concerns with logistical barriers, such as limited public transportation in the metro Detroit area, that hindered care seeking. Finally, many veterans interviewed for the project expressed discomfort with receiving treatment from civilian providers, who they felt do not have sufficient familiarity with the experience of being a veteran to provide adequate care.

With respect to mental health concerns in particular, veterans noted that many service members and veterans do not recognize that they suffer from mental health problems. They also said that perceived stigma can be a barrier to accessing care for those who do recognize they need help. Even when they do access care, some veterans felt that their mental health concerns were likely to be dismissed by the VA if they had not served in a combat position. Other concerns included issues around treatments - for example, overmedicationand worry that family members may be unprepared to support them with mental health problems.

\section{Mental Health Support Resources Available to Detroit Veterans}

A review of federal, state, county, and nongovernmental providers in the metro Detroit area indicates that access to specific resources may depend on the characteristics of an individual's military service and discharge status, distinguishing between those services that are available to veterans based on meeting certain eligibility requirements, and those available to all veterans, regardless of status.

For veterans who meet such conditions as minimum active service time and discharge "under conditions other than dishonorable," RAND identified several services and supports for those with mental health problems.

- Department of Veteran Affairs: Within the metro Detroit area, the John D. Dingell VA Medical Center is the largest provider of mental health care services for veterans and includes a wide array of programs dedicated to mental health. In addition to the main VA Medical Center, satellite clinics and centers through the surrounding counties offer varied mental health care services.

- State-based and state-funded resources: The Michigan Veterans Affairs Agency (MVAA), which is housed within the Michigan Department of Military and Veteran Affairs, works to decrease barriers and increase access to education, employment, health care, and improved quality of life for eligible veterans residing in Michigan. For veterans with an honorable discharge and at least 180 days of service during a period of war, the MVAA runs a program through the Michigan Veterans Trust Fund that pays for up to five community mental health service provider visits for a veteran who is eligible for federal benefits but not currently registered in the VA health care system.

- County-based services and resources: Each of the three counties composing the metro Detroit area has countylevel veteran affairs departments that facilitate access to federal and state benefits to veterans who are county residents. These county-level departments assist veterans and their families in applying for federal, state, and county benefits, while veterans with mental health-related needs are mostly referred to local vet centers or the VA Medical Center in Detroit.

- Nongovernmental organization services: The many veteran service organizations in metro Detroit focus primarily on helping connect veterans with each other and sharing information about the available benefits and services that support local veterans. While none of the organizations we identified provide mental health services directly, most offer referrals to relevant service providers. 
While the organizations listed above offer a significant number and diversity of services to veterans who meet specific eligibility criteria, a much smaller number of local organizations support veterans regardless of discharge status. Looking specifically at mental health services, veterans with a less than honorable discharge rely primarily on individual service providers in the metro Detroit area that may work through large health systems, in private clinics, or through solo practices; recent efforts have been made to increase awareness of and access to these providers. Community mental health agencies, such as the Detroit Wayne Mental Health Authority, also provide care, but their use by veterans is limited.

Beyond eligibility obstacles, discussions with stakeholders helped identify additional critical gaps in the provision of mental health services in metro Detroit. For example, restrictions related to the distribution and use of funding by community mental health agencies typically mean that veterans are redirected to the VA for mental health services. In addition, despite the variety and number of organizations working to support metro Detroit veterans, there are concerns that these entities operate independently from one another. Since 2013, MVAA's Veteran Community Action Team has been working to promote community collaboration to deliver service and support to veterans more effectively.

\section{Recommendations for Improving Support}

The following recommendations, for policymakers and other stakeholders, can help ensure that metro Detroit veterans are able to find and use critical mental health services. It is important to note that a comprehensive approach is needed to pursue the following recommendations simultaneously.

- Raising awareness: To strengthen support to veterans, stakeholders should work to increase awareness across diverse organizations_-including community-based mental health providers and other social services organizationsregarding the challenges faced by veterans and the services and benefits available to them. They also should work to empower veterans to take advantage of available mental health resources and services.

- Creating connections: Local website directories that complement the existing MVAA website, which primarily features federal- and state-level resources, can help connect veterans to available resources. Other approaches include enhanced one-stop navigation assistance, for example, through a call center (such as expanding the 1-800-MICH VET call center) or MVAA and other websites that link veterans with peers or social workers for a full range of referral support. In addition, stronger connections among service providers can increase the efficiency of their outreach efforts.

- Filling gaps in resources: Policies to address gaps—such as benefit and service eligibility restrictions on veterans with a less than honorable discharge status; limitations on the use of state-provided block grants to community mental health agencies; and limited capacity at vet centers to accommodate those interested in counseling servicescould expand access to high-quality services to veterans.

Veterans in the metro Detroit area face many of the same challenges as veterans in other communities across the country. However, a better understanding of this specific population of veterans, their specific mental health care needs, and the local services and support available to them are key tools to ensure that resources are reaching those in need. Future efforts to support veterans also should work to improve synergies and integration among existing services and providers, as well as work to assess or evaluate the impact of specific programs on veteran outcomes. These steps will be important to ensure that solutions are sustainable and effective. 


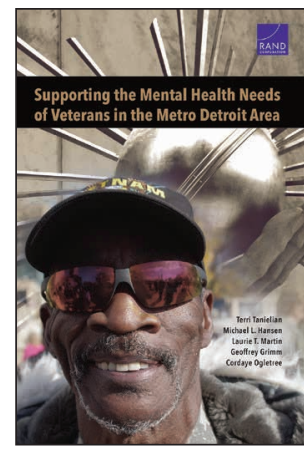

This brief describes work done in RAND Health documented in Supporting the Mental Health Needs of Veterans in the Metro Detroit Area, by Terri Tanielian, Michael L. Hansen, Laurie T. Martin, Geoffrey Grimm, and Cordaye Ogletree, RR-1346-WFW, 2016 (available at www.rand.org/t/RR1346). To view this brief online, visit www.rand.org/t/RB9887. The RAND Corporation is a research organization that develops solutions to public policy challenges to help make communities throughout the world safer and more secure, healthier and more prosperous. RAND is nonprofit, nonpartisan, and committed to the public interest. RAND's publications do not necessarily reflect the opinions of its research clients and sponsors. RAND ${ }^{\circledR}$ is a registered trademark. ๑ RAND 2016

Limited Print and Electronic Distribution Rights: This document and trademark(s) contained herein are protected by law. This representation of RAND intellectual property is provided for noncommercial use only. Unauthorized posting of this publication online is prohibited. Permission is given to duplicate this document for personal use only, as long as it is unaltered and complete. Permission is required from RAND to reproduce, or reuse in another form, any of our research documents for commercial use. For information on reprint and linking permissions, please visit www.rand.org/pubs/permissions.html. 